\title{
PSA Level Greater than Twenty
}

National Cancer Institute

\section{Source}

National Cancer Institute. PSA Level Greater than Twenty. NCI Thesaurus. Code C136646.

A blood concentration of prostate specific antigen greater than $20 \mathrm{ng} / \mathrm{mL}$. 